INTERNATIONAL RESEARCH JOURNAL OF PHARMACY

www.irjponline.com

ISSN $2230-8407$

Research Article

\title{
SAFETY PROFILE OF CONCOMITANT ADMINISTRATION OF ARTEMISININ BASED THERAPY AND CALCIUM COMPOUNDS IN LABORATORY ANIMALS
}

Mulambalah Chrispinus Siteti ${ }^{1 *}$, Siamba Donald Namasaka ${ }^{2}$, Ogutu Philip Ariya ${ }^{2}$

${ }^{1}$ Contacting and corresponding author, Moi University, College of Health Sciences, School of Medicine, Department of

Medical Microbiology and Parasitology, P. O. Box 4606 Post Code 30100 Eldoret, Kenya

${ }^{2}$ Masinde Muliro University of Science and Technology, Department of Biological Sciences, P.O. Box 190, Post Code 50100, Kakamega, Kenya

Email: csmulambalah@gmail.com

Article Received on: 12/03/13 Revised on: 09/04/13 Approved for publication: 01/05/13

DOI: $\mathbf{1 0 . 7 8 9 7 / 2 2 3 0 - 8 4 0 7 . 0 4 5 2 1}$

IRJP is an official publication of Moksha Publishing House. Website: www.mokshaph.com

(C) All rights reserved.

\section{ABSTRACT}

Artemisinin based combination therapy (ACT) specifically artemisinin-lumefantrine recommended for human malaria treatment may be prescribed for patients who are on calcium supplements unknowingly. The interaction of the two and end result on body metabolic and physiological process is not known. There is need to assess the safety and possible adverse effects of separate and combined administration of these agents. Randomized groups of experimental and control rats were used to evaluate the interaction of the two. Two of the groups of rats were placed on calcium supplement for one month after which ACT was orally administered to one of the group for 3-6 days. Another group of rats not on calcium supplement was administered with ACT only. The control group of rats was administered with sterile distilled water and kept at same laboratory conditions as experimental groups. Levels of $\mathrm{Na}^{+}$, $\mathrm{Ca}^{2+}, \mathrm{K}^{+}$, creatinine and urea were analyzed in plasma of all groups of rats. Concomitant use of artemisinin-lumefantrine and calcium supplement induced significant elevation of plasma $\mathrm{Na}^{+}, \mathrm{Ca}^{2+}$ and creatinine concentrations. Extended and possibly repeated use of ACT alone raised the plasma $\mathrm{Na}^{+}$and creatinine level above the normal value after the first three days. It was concluded that repeated and or prolonged use of artemisinin-lumefantrine alone and in combination with calcium lead to renal dysfunction in laboratory animals. Our findings highlight areas that require clarification by long term studies and provide a basis for further research and recommend that related studies be carried out in human subjects for comparison with these findings.

Keywords: Artemisinin, malaria, calcium, creatinine, urea, renal dysfunction.

\section{INTRODUCTION}

Malaria is a parasitic disease caused by protozoans in the genus Plamodium. The disease is currently a world-wide serious public health problem more so in tropical and subtropical regions with more than one million lives lost every year ${ }^{1}$. It is the second most serious public health problem in Kenya after HIV/ADS. The two diseases, human malaria and HIV/AIDS as co-infections are lethal, infected individuals deteriorate rapidly and die in the absence of prompt and appropriate treatment. Antimalarial drug resistance has created serious problem in the management of malaria cases by limiting the number of antimalarial drugs available for chemotherapy and chemoprohylaxis. Presently, artemisinin extracts and derivatives are recommended first line drugs for treatment of malaria cases in Kenya and many countries in Africa. Artemisinin-based combination therapies (ACTs) are known for rapid cure of all malaria cases including drugresistant falciparum cases $^{2}$. Kenya has many malaria endemic regions where it is possible for extended and repeated use of ACTs in patients who could be on calcium supplements or other forms of treatments involving calcium compounds for instance management of osteoporosis. Calcium is also an ingredient in many antacids and is also used commonly to control high levels of magnesium, phosphorous and potassium in blood.

Artemisinin based drugs have short half-life and are mainly metabolized in the liver and excreted by the kidneys. In combination with other drugs of longer half life, ACTs can stay in body tissues and in circulation longer. Therefore there is need to evaluate and analyze the safety profile of the ACTs alone, in combination with other drugs and possible outcome with interaction with other compounds in the body when used for longer time than necessary.
Among the artemisinin-based combination therapies, artemether - lumefantrine is regarded as a therapeutic agent of choice in all case of malarial treatment ${ }^{3,4}$. Animal studies indicate that extended and repeated use of the drug caused neurotoxic effects such as gait disturbances, loss of spinal and pain reflexes, ${ }^{5,6,7}$. Artemether-lumefantirne has been associated with generation of potentially destructive and toxic free radicals ${ }^{8}$. An assessment of Artemether alone is reported to cause anorexia, reduction in the food and water intake, increased urine output without a corresponding increase in the water intake in experimental rats 9 . The accompanying dehydration could be possible cause of adverse effect on the ionic balance of the body fluids in laboratory animals. Presently, there is inadequate information on the possible effect of artemisinin- based combination therapy on the plasma levels of electrolytes in animal body fluids, tissues and effect on kidney functions.

Faced with many cases of malaria patients who require prompt treatment, health professionals prescribe artemisininbased combination medication as first choice treatment. In the aged and elderly with osteoporosis, malaria treatment with ACTs may require supplementation with calcium in the range of 1000 to $1500 \mathrm{mg} / \mathrm{d}^{10}$. The use of calcium supplements has been linked with cardiovascular defects and changes in plasma components and electrolytes ${ }^{9,11}$. As the world population of elderly people increases due to improved healthcare services, there is increased need for calcium supplements to manage cases of osteoporosis. The same population segment may at some point in time require both malaria and osteoporosis management. There is inadequate biomedical data to quantify the safety of repeated use of ACT and calcium compounds separately and when coadministered hence further studies are warranted. The purpose of the study was to investigate the safety of 
combined use of ACTs and calcium supplements as the case may be in the management of both human malaria and osteoporosis.

\section{MATERIALS AND METHODS \\ Sourcing of Artemether-Lumefantrine and Calcium Compound}

The artemesinin combined drug was sourced as Leonart ${ }^{\circledR}$ from Bliss GVS Pharma Ltd. India, composed of $80 \mathrm{mg}$ Artemether and 480mg lumefantrine. Calcium compound was sourced from GNLD Int. Spartan, South Africa as 300mg calcium glycinate).

\section{Experimental Animals Handling and Care}

Rats were the preferred experimental animals due to their quick adaption to laboratory conditions, large quantity of tissue, convenient size and readily available. One hundred and twenty (120) 4-week old male Wistar rats weighing 100$150 \mathrm{~g}$ obtained from the veterinary research centre, Muguga, Kenya were used. All experimental and control rats were kept in individual cages in an environmentally controlled room with a $12 \mathrm{~h}$ light $/ 12 \mathrm{~h}$ dark cycle. The rats were fed on standard rat feed pellets and clean treated drinking water. All rats used in the study were acclimatised to laboratory conditions for two weeks before experimentation. The care of the animals was in accordance with guidelines for care of laboratory animals ${ }^{12}$.

\section{Experimental Design and Drug Administration}

The rats were randomized into four (4) groups of 30 rats each appropriately labeled, categorized and treated as indicated in Table 1. Calcium supplements were administered orally at a therapeutic dose of $10 \mathrm{mg} / \mathrm{kg}$ body weight twice daily to rats in category $\mathrm{C}$ and $\mathrm{D}$ while ACT was administered at a therapeutic dose of $2.67 \mathrm{mg}$ artemether/16mg lumefantrine per Kg body weight twice daily to rats in category B and D. The anti-malarial drug combination, ACT was agitated for homogeneity and administered as an aqueous suspension by oral gavage. Calcium supplement was first administered continuously for thirty days. Artemether-lumefantrine was introduced beginning from the thirty first day, such that both the drug and calcium supplements were simultaneously administered continuously for the next three days to rats in category B and D.

\section{Blood Collection and Preparation of Plasma Samples}

After the last treatment, half (15) rats in each category were denied food for twelve hours and later sacrificed by exposure to cotton wool soaked in ether. Blood was immediately drawn through cardiac puncture and introduced into heparinised capillary tubes. Plasma was prepared by centrifugation at $3000 \mathrm{rpm}$ for 10 minutes. Treatment was continued with the remaining rats for another three days after which they were also fasted for twelve hours and then sacrificed. Blood was also drawn and similarly processed to obtain serum.

\section{Biochemical Tests and Statistical Analysis}

The concentrations of $\mathrm{Na}^{+}$and $\mathrm{K}^{+}$in plasma were determined by Flame Photometry using Coming 410C Flame Photometer. The $\mathrm{Ca}^{2+}$ level was measured using Cresolphthalein Complexone method as described by Burtis and Ashwood ${ }^{13}$. A modified Jaffe method Spencer ${ }^{14}$ was used for estimating plasma creatinine while urea was determined by using urease enzyme to enzymatically catalyse the hydrolysis of urea, followed by detection of ammonia by colour reactions as described by Francis ${ }^{15}$.

Data analyses were performed using SPSS software (SPSS 10.0 for Windows, SPSS Inc, Chicago, IL). All data are expressed as mean \pm SEM. Analysis of variance was used to test for differences between the groups. Duncan's multiple range test was used to determine the levels of significance of the differences among the mean values at $\mathrm{p}<0.05$.

\section{RESULTS}

There was no appreciable change in sodium ion concentration in plasma after the initial three days treatment with ACT, whereas a significant increase from the normal control value of $132.6 \pm 5.9 \mathrm{mmol} / \mathrm{L}$ to $158.9 \pm 2.9 \mathrm{mmol} / \mathrm{L}$ was observed in rats on calcium supplement treatment (Table 2). Combined calcium treatment with ACT significantly $(\mathrm{p}<0.05)$ increased the sodium ion concentration to $175.3 \pm 4.1 \mathrm{mmol} / \mathrm{L}$. After continued treatment for another three days, sodium ion concentration increased significantly with ACT administration. The observed concentration of $145.5 \pm 2.1$ $\mathrm{mmol} / \mathrm{L}$ was higher than the value of $129.5 \pm 4.9 \mathrm{mmol} / \mathrm{L}$ recorded after the initial three days treatment. A similar increase was recorded in rats on calcium supplement treatment; but the sodium ion concentration of $162.3 \pm 4.8$ $\mathrm{mmol} / \mathrm{L}$ was not the same as recorded value after the $30^{\text {th }}$ day of treatment. The results suggest that sodium ion concentration in rats on calcium supplement and simultaneously administered with ACT was higher than the concentration in rat placed on ACT alone. The recorded figure of $189.1 \pm 2.2 \mathrm{mmol} / \mathrm{L}$ was significantly higher in the same group of rats when compared to recorded value after the initial three days treatment.

The plasma potassium ion concentration was not altered after the initial three days treatment with ACT (Table 3). Neither separate treatment calcium supplement alone nor combined treatment with calcium and ACT significantly altered the plasma potassium ion concentration. However, when the rats were further treated for three days with ACT, an increased in plasma potassium ion concentration was observed in rats separately placed on ACT and those placed on calcium supplementation when compared with the normal control group. The observed plasma potassium ion concentration of $5.5 \pm 0.02 \mathrm{mmol} / \mathrm{L}$ in rats placed on calcium supplement and simultaneously treated with ACT was however significantly higher than that of all other treatment groups. It was also higher than the value obtained in the same group (category D) after the initial three days administration of ACT.

Artemisinin combination therapy alone did not significantly alter plasma calcium ion level (Table 4). The plasma calcium ion concentration of $2.5 \pm 0.03 \mathrm{mmol} / \mathrm{L}$ and $2.1 \pm 0.1 \mathrm{mmol} / \mathrm{L}$ recorded after the $3^{\text {rd }}$ and $6^{\text {th }}$ day of continuous administration of ACT were not significantly different from that of control rats. After thirty days of continuous calcium supplement treatment, plasma calcium ions increased in rats in category $\mathrm{C}$ to $3.8 \pm 0.04 \mathrm{mmol} / \mathrm{L}$. This recorded value was significantly higher than that of control at $2.5 \pm 0.04 \mathrm{mmol} / \mathrm{L}$. The plasma calcium concentration of $3.6 \pm 0.1 \mathrm{mmol} / \mathrm{L}$ in the group of rat co-treated with ACT and calcium supplement was not significantly different from that of the rats on calcium treatment alone. The recorded value was not significantly altered after six days of co-administration of calcium and ACT. 
Table 1: Experimental animal treatment

\begin{tabular}{|c|c|c|}
\hline Category & Number of Rats Used (n) & Treatment(s) \\
\hline A (Control normal) & 30 & Sterile distilled water. \\
\hline B (Experimental) & 30 & Artemether-lumefentrine only. \\
\hline C (Experimental) & 30 & Calcium supplements only \\
\hline D (Experimental) & 30 & Artemether-lumefantrine and calcium supplements. \\
\hline TOTAL & 120 & \\
\hline
\end{tabular}

Table 2: Effect of treatment on plasma sodium concentration

\begin{tabular}{|c|c|c|}
\hline Category and Treatment & After $3^{\text {rd }}$ day of continuous ACT administration & ${\text { After } 6^{\text {th }} \text { day of continuous administration. }}$ \\
\hline A (Normal control) & $132.6 \pm 5.9$ & $129.8 \pm 2.9$ \\
\hline B (ACT only) & $129.5 \pm 4.9$ & $145.4 \pm 2.1$ \\
\hline C (Calcium only) & $158.9 \pm 2.9$ & $162.3 \pm 4.9$ \\
\hline D (calcium + ACT) & $175.3 \pm 4.1$ & $189.3 \pm 2.2$ \\
\hline
\end{tabular}

Units of measurement are $\mathrm{mmol} / \mathrm{L}$

Values are mean \pm standard deviation of mean of analyzed samples.

Table 3: Effect of treatment on plasma potassium concentration

\begin{tabular}{|c|c|c|}
\hline Category and Treatment & After $3^{\text {rd }}$ day of continuous ACT administration & After $6^{\text {th }}$ day of continuous administration \\
\hline A (Normal control) & $4.6 \pm 0.2$ & $4.5 \pm 0.1$ \\
\hline B (ACT only) & $4.8 \pm 0.2$ & $5.1 \pm 0.3$ \\
\hline C (Calcium only) & $4.4 \pm 0.1$ & $4.9 \pm 0.1$ \\
\hline D (Calcium + ACT) & $4.4 \pm 0.1$ & $5.5 \pm 0.02$ \\
\hline
\end{tabular}

Units of measurement are $\mathrm{mmol} / \mathrm{L}$

Values are mean \pm standard deviation of mean of analyzed samples.

Table 4: Effect of treatment on plasma calcium concentration

\begin{tabular}{|c|c|c|}
\hline Category and treatment & After $3^{\text {rd }}$ day of continuous ACT administration & After $6^{\text {th }}$ day of continuous administration \\
\hline A (Normal control) & $2.5 \pm 0.04$ & $2.5 \pm 0.04$ \\
\hline B (ACT only) & $2.5 \pm 0.03$ & $2.1 \pm 0.12$ \\
\hline $\mathrm{C}$ (Calcium only) & $3.75 \pm 0.04$ & $3.7 \pm 0.05$ \\
\hline $\mathrm{D}($ Calcium $+\mathrm{ACT})$ & $3.6 \pm 0.06$ & $3.6 \pm 0.10$ \\
\hline
\end{tabular}

Units of measurement are $\mathrm{mmol} / \mathrm{L}$

Values are mean \pm standard deviation of mean of analyzed samples.

Table 5: Effect of treatment on plasma creatinine concentration

\begin{tabular}{|c|c|c|}
\hline Category and treatment & After 3 $^{\text {rd }}$ day of continuous ACT administration & ${\text { After } 6^{\text {th }} \text { day of continuous administration }}$ \\
\hline A (Normal control) & $66.3 \pm 4.0$ & $67.5 \pm 4.04$ \\
\hline B (ACT only) & $72.5 \pm 5.9$ & $85.1 \pm 6.12$ \\
\hline C (Calcium only) & $77.7 \pm 4.98$ & $79.7 \pm 5.05$ \\
\hline D (Calcium + ACT) & $82.5 \pm 4.06$ & $82.6 \pm 0.10$ \\
\hline
\end{tabular}

Units of measurement are $\mathrm{mmol} / \mathrm{L}$

Values are mean \pm standard deviation of mean of analyzed samples.

Table 6: Effect of treatment on plasma urea concentration

\begin{tabular}{|c|c|c|}
\hline Category and treatment & After $3^{\text {rd }}$ day of continuous ACT administration & ${\text { After } 6^{\text {th }} \text { day of continuous administration }}$ \\
\hline A (Normal control) & $12.5 \pm 0.4$ & $12.5 \pm 0.1$ \\
\hline B (ACT only) & $12.5 \pm 0.3$ & $12.1 \pm 0.1$ \\
\hline C (Calcium only) & $12.5 \pm 0.3$ & $12.7 \pm 0.2$ \\
\hline E (Calcium + ACT) & $12.3 \pm 0.1$ & $12.6 \pm 0.1$ \\
\hline
\end{tabular}

Units of measurement are $\mathrm{mmol} / \mathrm{L}$

Values are mean \pm standard deviation of mean of analyzed samples.

Separate treatment with ACT did not affect plasma creatinine levels as determined after three days of continuous treatment (Table 5). Placement on calcium supplement alone however increased the plasma creatinine level to $77.7 \pm 4.9 \mathrm{mmol} / \mathrm{L}$ which was significantly higher than $66.3 \pm 4.0 \mathrm{mmol} / \mathrm{L}$ obtained in the normal control group. Combined treatment with calcium and ACT was also observed to have raised the plasma concentration of calcium to $82.5 \pm 4.1 \mathrm{mmol} / \mathrm{L}$ but the value obtained was not different from that of rats placed on calcium supplement alone. After six days of continuous treatment with ACT, the plasma creatinine value was increased to $85.1 \pm 6.1 \mathrm{mmlol} / \mathrm{L}$ which was significantly higher than the normal control value of $67.5 \pm 4.0 \mathrm{mmol} / \mathrm{L}$ and was also higher than the value observed after the initial three days treatment. Though higher than the normal control value, the observed plasma creatinine concentration after six days of
ACT administration to rats on calcium supplement was not different from the value (in the same group of rat) after the initial three days treatment with ACT nor was it different from that of rat on calcium supplement alone.

Neither separate administration of ACT and calcium supplement nor their combined administration was found to have changed the plasma urea level significantly after three days of continuous administration (Table 6). Treatment with ACT continuously for another three days was also observed not to have altered the plasma urea level significantly.

\section{DISCUSSION AND CONCLUSION}

Previous studies indicate that the plasma levels of electrolytes, namely sodium $\left(\mathrm{Na}^{+}\right)$, potassium $\left(\mathrm{K}^{+}\right)$, and calcium $\left(\mathrm{Ca}^{2+}\right)$ are important for the proper functioning of the neuromuscular and cardiovascular system ${ }^{9,16,17}$. Excessive 
loss of these ions from the body lead to serious deleterious effects on the concerned systems ${ }^{18,19}$. The study finding thus corroborates related reports on the cardiovascular disease risk induced by increased calcium supplementation ${ }^{11}$. Another electrolyte, sodium is an abundant extracellular ion, and plays an important role in muscle contraction. Similarly, potassium, an another intracellular ion, plays an important role in muscle contraction and regulation of the heart beat ${ }^{18,19}$. The electrolyte derangement as evident by increased plasma concentration of sodium, potassium and calcium reported in the present study suggest that continuous supplementation with calcium and prolonged use of ACT alone and in combination with calcium supplement could present a risk for arrhythmia, abdominal pain and cramping, and muscle weakness.

Elevated plasma sodium level (hypermatermia), plasma potassium level (hyperkalemia), plasma calcium level (hypercalcemia) and elevated serum urea and enzyme creatine kinase levels are commonly used as indices of acute renal failure ${ }^{20}$. Potassium, once absorbed by the intestinal tract, is partially removed from the plasma by glomerular filtration and nearly completely reabsorbed in the proximal tubule. Unlike sodium, it is effectively re-excreted by the distal tubules of the kidneys. Our findings suggest a major elevation in plasma sodium level with administration of artemisinin-lumefantrine combination and also with prolonged use of calcium supplements. This suggests that continuous use of these medications can alter renal function. The findings are comparable to previous studies on artemisinin ${ }^{8,9}$. Currently there are no major reported cases of alteration in plasma potassium with therapeutic use of ACT. But our findings however, suggest that prolonged use of the drug may predispose to hyperkalemia due to differences in the renal handling of the electrolytes.

The kidney is known to function as an organ responsible for regulation of calcium fluxes, however, it has limited capacity to handle large changes in the serum calcium levels. Over seventy percent of the calcium filtered through the glomeruli is reabsorbed in the proximal tubules by a process linked to sodium re-absorption. Approximately $20-25 \%$ of filtered calcium is reabsorbed in the ascending limb of the loop of Henle, whereas the remaining $10 \%$ is reabsorbed under the influence of parathyroid hormone (PTH) and vitamin D in the distal tubule ${ }^{18}$. In the present study, it was noted that there was no alteration in plasma calcium concentration with artemisinin-lumefantrine based combination administration. It was however noted that a significant increase in the plasma calcium level with calcium supplementation and when calcium supplement was combined with the ACT. This suggests that arteminsinin-lumefantrine based combination may not induce a significant alteration in calcium homeostasis but that calcium supplement will. The increased plasma calcium recorded with calcium supplementation could be attributed to the increased calcium overload such that the kidneys fail to efficiently handle. Serum calcium homeostasis is regulated by a rapid negative feedback hormonal pathway involving the concentration of ionized calcium in serum and the secretion of parathyroid hormone from the parathyroid gland. A decline in serum calcium inactivates the calcium receptor in the parathyroid gland cells and increases PTH secretion, which restores serum calcium by activating the parathyroid receptor in bone, to increase calcium re-absorption, and in kidney, to increase tubular calcium re-absorption. In the kidney, the increased PTH secretion augments its calcium-restorative effect by increasing secretion of 1,25-dihydroxy vitamin $\mathrm{D}$ $\left(1,25(\mathrm{OH})_{2} \mathrm{D}\right)$, which, acting on the vitamin $\mathrm{D}$ receptor in gut, increases active calcium absorption and increases calcium reabsorption into the bones. A decline in serum calcium inactivates the calcium receptors in the parathyroid glands to increase PTH secretion, which acts on the parathyroid receptor (PTHR) in kidney to increase tubular calcium reabsorption, and in bone to increase net bone re-absorption. The increased PTH also stimulates the kidney to increase secretion of $1,25(\mathrm{OH})_{2} \mathrm{D}$, which increase calcium absorption, in the parathyroid glands and decrease PTH secretion, and in bone to increase re-absorption.

Creatinine clearance calculated from creatinine concentrations in urine and plasma samples, as well as urea clearance, is commonly used to determine the glomerular filtration rate of the kidneys. Therefore, creatinine clearance is a useful test for renal function. Thus, plasma concentrations of creatinine and urea could be used as indicators of nephrotoxicity ${ }^{21}$. Low clearance of creatinine or/and urea indicate a diminished and impaired ability by the kidneys to filter these waste products from the blood and excrete them in urine. As their clearance values decrease, their blood levels increase. Hence, an abnormally elevated blood creatinine is diagnostic of impaired renal function $^{22,23,24}$. Based on our findings it is possible that prolonged use of artemisinin-lumefantrine, continuous intake of calcium supplement and combined use of artemisininlumefantrine and calcium supplement may result in elevated plasma creatinine level thus suggesting a disposition to renal failure.

Urea is the main and final catabolite of nitrogen compounds in humans and animals. It is produced as a breakdown product of protein. High urea levels could suggest impaired kidney function. This may arise due to acute or chronic kidney disease ${ }^{25}$. Our result does not indicate any alteration in plasma urea neither with artemisinin-lumefantrine use nor with calcium supplementation. This however may not suggest normal kidney function during treatment and requires elaboration through long term studies beyond the scope of the present study. Although most of the urea is completely filtered by the kidney, unfortunately not all of it is also reabsorbed. This may lead to gross underestimation of gross glomerular filtration rate (GFR) ${ }^{25}$ hence further research necessary to arrive at a clear explanation.

We conclude that changes do occur in plasma electrolytes when ACTs and calcium supplements are co-administered. These changes in plasma electrolytes as indices of renal function demonstrate that calcium supplement and prolonged used of ACT can induce renal damage and consequently renal dysfunction in laboratory animals. We suggest that related studies be carried out in human subjects for comparisons with these findings.

\section{ACKNOWLEDGMENTS}

We acknowledge and appreciate Dr. J.M. Vulule of Kenya Medical Research Institute, and others for critically reviewing the manuscript and suggestions that have been incorporated in the article.

\section{REFERENCES}

1. Godwin OA, Sina I, Evelyn IE. Effects of some Nigerian antimalarial medicinal plants on glucose levels in wistar rats. Arch. App. Sci. Res. 2: $2010112-116$

2. Lokesh CM, Mit BC, Virenda KB. Antiplas interactions between artemisinin and triclosan or ketoconazole combinations against blood stages of Plasmodium falciparum in vitro. Am. J. Trop. Med. Hyg. 76: 2007 497-501. 
3. Van Vugt MP, Wilariratana B, Gemperti IG, Gathman L, Phaipum A Brockman AC, Luxemburger NJ, White F, Nosten G, Looareesuwan S. Efficacy of six doses of artemether-lumefantrine (Benflumetol) in multidrug-resistant plasmodium falciparum malaria Am. J. Trop. Med. Hyg.60: 1999 736-742.

4. Nosten F, Van Vugt M, Prince R, Luxemburger C, Thyway KL, Brockman A, McGready R, Kuile F, Looareesuuvan S, White NJ. Effects of artesimate-mefloquine combination on incidence of plasmodium falciparum malaria and mefloquine resistance in Western Thailand; A prospective study. Lancet 356: 2000 297-302. http:/ /dx.doi.org/10.1016/S0140-6736(00)02505-8

5. Petras JM, Kyle DE, Gettayacamin M, Young GD, Bauman RA, Webster HK, Corcoran KD, Peggins JD, Vane MA, Brewer TG. Arteether; Risk of two-week administration of Macaca mulatta. Am. J. Trop. Med. Hyg. 34: 1997 390-396.

6. Nontprasert A, Sasithon P, Marika N, Sirivan V, Nicholas JW. Studies of the neurotoxicity of oral artemisinin derivatives in mice. Am. J. Trop. Med. Hyg.62: 2000 409-412.

7. Xiao SY, Yang Q, You J, Utzinger H, Guo J, Peiying J, Mei J, Guo R, Bergquit C, Tanner M . Potential long-term toxicity of repeated orally administered doses of artemether in rats. Am. J. Trop. Med. Hyg.66: 2002 30-34.

8. Akomolafe RO, Adeoshun IO, Fakunle JB, Iwalewa EO, Ayoka AO, Akanji. Changes in the visceral functions of plasmodium-infected and uninfected rats following administration of artemether. Clin. Exp. Pharmacol. Physiol. 33: 2006 1180-1183. http://dx.doi.org/ $10.1111 / \mathrm{j} .1440-1681.2006 .04496 . x$

9. Akomolafe RO, Adeoshun IO, Fakunle JB, Iwalewa EO, Ayoka AO, Ajayi EO, Odeleye OM, Akanji BO. Effects of artemether on the plasma and urine concentrations of some electrolytes in rats. Afr. J. Biotech. 10: 2011 4226-33.

10. McCabe GP, Johnston CC, Weaver CM, Peacock M. Dairy intakes affect bone density in the elderly. Am. J. Clin. Nutr. 80: 2004 10661074.

11. Ajani EO, Salau BA, Bamisaye FA (2012). Plasma and hepatic lipid profile of rats in response to separate and combined administration of calcium and artemisin-based combination drug. Book of Abstract, $32^{\text {nd }}$ Annual Conference, Nigerian Society of Biochemistry and Molecular Biology.

12. WHO, Guidelines for Breeding and care of laboratory animals Document number WHO/ZOON./93 1993.
13. Burtis CA, Edward RA. Tietz textbook of clinical chemistry. Philadelphia, PA: W.B. Saunders Company. Wallach J. 7th ed. Philadelphia. 1999 pp 24-32.

14. Spencer K. Analytical reviews in clinical biochemistry: the estimation of creatinine. Ann. Clin Biochem.23: 1986 1-25.

15. Francis PS, Lewis SW, Lim KF. Analytical methodology for the determination of urea: current practice and future trends. Trends Anal. Chem. 21: $2002 \quad 389-400 . \quad$ http://dx.doi.org/10.1016/S01659936(02)00507-1

16. Saka WA, Akhigbe RE, Popoola OT, Oyekunle OS. Changes in Serum Electrolytes, Urea, and Creatinine in Aloe Vera-treated Rats. J Young Pharm. 4: 2012 78-81. http://dx.doi.org/10.4103/0975-1483.96620

17. Agoreyo FO, Nwanze N. Plasma sodium and potassium changes in sickle cell Patients. Int. J. Gen. and Mol. Bio. 2: 2012 014-019.

18. Ganong E. Review of medical physiology $21^{\text {st }}$ Edition. Lange Medical Books/Mc Graw Hill. 2003 pp. 701-733.

19. Guyton AC, Hall JE. Textbook of Medical Physiology. Tenth Edition. Harcourt International Edition. Published by W.B. Saunders Company, Philadelphia, Pennsylvania. 2005 pp. 377-455.

20. Lameire N. The pathophysiology of acute renal failure. Crit. Care Clin. 2005 21:197-200. http://dx.doi.org/10.1016/j.ccc.2005.01.001

21. Pagana KD, Louis MO (1998). Mosby, Inc; Mosby's manual of diagnostic and laboratory tests.

22. Mackenzie W. Urea Metabolism in Chronic Renal Failure. The J, Clin. Inve. 53: 1974 1385-1392. http://dx.doi.org/10.1172/JCI107687

23. Burtis CA and Ashwood ER. Tietz fundamentals of clinical chemistry. W.B. Saunders Co. Philadelphia USA. 2001 pp. 598-640.

24. Henry JB. Clinical diagnosis and management by laboratory methods. 20th ed. Philadelphia, PA W. B. Saunders Company. in body fluids of mammals by reversed-phase ultra-fast liquid chromatography. Czech. J. Anim. Sci.57: 2012 19-2

25. Czauderna M, Kowalczyk J. Simple, selective, and sensitive measurement of urea in body fluids of mammals by reversed-phase ultra-fast liquid chromatography. Czech. J, Anim. Sci, 57: 2012 19-21

Cite this article as:

Mulambalah Chrispinus Siteti, Siamba Donald Namasaka, Ogutu Philip Ariya. Safety profile of concomitant administration of Artemisinin based therapy and calcium compounds in laboratory animals. Int. Res. J. Pharm. 2013; 4(5):106-110 